\title{
HIPEC Methodology and Regimens: The Need for an Expert Consensus
}

\author{
Aditi Bhatt, MS, $\mathrm{MCh}^{1}$, Ignace de Hingh, $\mathrm{MD}, \mathrm{PhD}^{2}$, Kurt Van Der Speeten, $\mathrm{MD}, \mathrm{PhD}^{3}$, \\ Martin Hubner, MD, $\mathrm{PhD}^{4}$, Marcello Deraco, $\mathrm{MD}, \mathrm{PhD}^{5}$, Naoual Bakrin, $\mathrm{MD}$, $\mathrm{PhD}^{6}$, Laurent Villeneuve, $\mathrm{MBE}$, \\ $\mathrm{PhD}^{7}$, Shigeki Kusamura, $\mathrm{MD}, \mathrm{PhD}^{5}$, and Olivier Glehen, $\mathrm{MD}, \mathrm{PhD}^{6}$ \\ ${ }^{1}$ Department of Surgical Oncology, Zydus Hospital, Ahmedabad, India; ${ }^{2}$ Department of Surgical Oncology, Catharina \\ Hospital, Eidhoven, The Netherlands; ${ }^{3}$ Department of Surgical Oncology, Zeikenhuis Oost-Limberg, Genk, Belgium; \\ ${ }^{4}$ Department of Visceral Surgery, Lausanne University Hospital CHUV, Lausanne, Switzerland; ${ }^{5}$ Department of Surgical \\ Oncology, Fondazione IRCCS Istituto Nazionale dei Tumori, Milan, Italy; ${ }^{6}$ Department of Surgical Oncology, Centre \\ Hospitalier Lyon-sud, Lyon, France; ${ }^{7}$ Department of Clinical Research, Hospices Civils de Lyon, Centre Hospitalier Lyon- \\ sud, Lyon, France
}

\begin{abstract}
Background. Hyperthermic intraperitoneal chemotherapy (HIPEC) is performed with a wide variation in methodology, drugs, and other elements vital to the procedure. Adoption of a limited number of regimens could increase the collective experience of peritoneal oncologists, make comparison between studies more meaningful, and lead to a greater acceptance of results from randomized trials. This study aimed to determine the possibility of standardizing HIPEC methodology and regimens and to identify the best method of performing such a standardization.

Methods. A critical review of preclinical and clinical studies evaluating the pharmacokinetic aspects of different HIPEC drugs and drug regimens, the impact of hyperthermia, and the efficacy of various HIPEC regimens as well as studies comparing different regimens was performed.

Results. The preclinical and clinical data were limited, and studies comparing different regimens were scarce. Many of the regimens were neither supported by preclinical rationale or data nor validated by a dose-escalating formal phase 1 trial. All the regimens were based on
\end{abstract}

(C) Society of Surgical Oncology 2021

First Received: 19 February 2021

Accepted: 1 May 2021;

Published Online: 17 June 2021

O. Glehen, $\mathrm{MD}, \mathrm{PhD}$

e-mail: olivier.glehen@chu-lyon.fr pharmacokinetic data and did not take chemosensitivity of peritoneal metastases into account. Personalized medicine approaches such as patient-derived tumor organoids could offer a solution to this problem, although clinical validation is likely to be challenging.

Conclusions. Apart from randomized trials, more translational research and phases 1 and 2 studies are needed. While waiting for better preclinical and clinical evidence, the best way to minimize heterogeneity is by an expert consensus that aims to identify and define a limited number of regimens for each indication and primary site. The choice of regimen then can be tailored to the patient profile and its expected toxicity and the methodology according regional factors.

\section{EVOLUTION OF INTRAPERITONEAL CHEMOTHERAPY AND CURRENT INDICATIONS FOR ITS USE}

Intraperitoneal chemotherapy (IPC) was developed in the 1980s when the use of intravenous (systemic) chemotherapy treatment for peritoneal metastases (PMs) was producing dismal results, and regional chemotherapies with or without hyperthermia were being developed for different tumors. ${ }^{1,2}$ It was assumed that PMs are poorly vascularized compared with metastases at other sites due to drugs unable to reach the tumor site, leading to a comparatively poorer response to systemic chemotherapy (SC). ${ }^{3}$ Intraperitoneal chemotherapy would allow direct exposure of the tumor nodules to the 
chemotherapeutic agent, and the two-compartment model of drug transport across the peritoneal membrane supported this therapeutic rationale. ${ }^{4-6}$

Research has demonstrated that the peritoneum is a wellvascularized structure and that the reason for a poor response is not only inability to deliver the drug to the tumor, but most likely also the inherent chemoresistance of the tumor cells resulting from an adverse molecular profile. ${ }^{7,8}$ Peritoneal metastases arising from low-grade appendiceal mucinous tumors are of the low-grade variety and therefore respond poorly to SC. ${ }^{9}$ In contrast to this, $\mathrm{PMs}$ in ovarian cancer have a high response rate $(80 \%)$ to $\mathrm{SC}$, with $10-15 \%$ of patients experiencing a pathologic complete response. ${ }^{10-11}$

Patients with extensive PMs are symptomatic more often than their counterparts with metastases at other sites. $^{12}$ The symptoms of PMs have a negative impact on quality of life and performance status, making it more difficult to administer aggressive systemic therapies. Improvement in imaging and identification of risk factors for the development of PMs have led to an increase in early diagnosis of PMs when they are likely to be more responsive to $\mathrm{SC}$. $^{13-15}$ This coupled with the development of more effective $\mathrm{SC}$ regimens during the last 30 years has led to an improvement in the outcomes with SC alone as well as the combination of surgery and SC. ${ }^{16-18}$

Despite the progress in systemic therapies, surgery remains the cornerstone of potentially curative treatment for patients with PMs irrespective of the primary tumor site. Regional chemotherapy or IPC has a role to play in addition to surgery and systemic chemotherapy.

\section{MODES OF INTRAPERITONEAL DRUG DELIVERY}

The three most common modes for administering IPC are instillation of multiple doses through an intraperitoneal catheter (port-directed IPC or normothermic IPC [NIPEC]), multiple applications of aerosolized chemotherapy with raised intraabdominal pressure (pressurized intraperitoneal chemotherapy [PIPAC]), and intraoperative application of chemotherapy agents during surgery using hyperthermia (hyperthermic intraperitoneal chemotherapy [HIPEC]), usually performed only once. ${ }^{19}$ The current indications for the use of IPC are summarized in Table 1.

\section{IS INTRAPERITONEAL ADMINISTRATION OF CHEMOTHERAPEUTIC AGENTS A SOUND THERAPEUTIC RATIONALE?}

Intraperitoneal chemotherapy entails off-label use of drugs meant for intravenous administration. The theoretical benefits apart from a direct exposure of tumor cells to the drug are a prolonged retention of the drug in the peritoneal cavity, resulting in prolonged exposure of the peritoneal surfaces to the drug and a decreased systemic absorption resulting in reduced systemic toxicity. ${ }^{36,37}$ Thus, IPC allows higher drug doses to be administered without the resultant systemic toxicity.

Another possible mechanism often ignored is possible access of IPC to the peritoneal lymphatics, thus acting on translymphatic tumor spread. ${ }^{38,39}$

For all three modes of intraperitoneal (IP) administration, despite uneven distribution of the chemotherapy solution in the peritoneal cavity, a therapeutic benefit has been observed. ${ }^{40,41}$ Access to the transperitoneal lymphatics enables the drug to reach all areas because these lymphatics are connected subperitoneally.

The depth of conventional IPC penetration usually is not more than $3 \mathrm{~mm}$, but may reach $6 \mathrm{~mm}$ around the microinjection pump in PIPAC. ${ }^{42,43}$ Thus, it acts best in the presence of minimal or no residual disease. After complete cytoreductive surgery (CRS), IPC can address the free intraperitoneal cancer cells more effectively, reducing the implantation of these cells at the surgical site.

However, all three modes of IPC have shown benefits in the neoadjuvant/palliative setting also in the presence of gross disease, used either alone or in combination with SC. ${ }^{4-47}$ The IPC may be acting on the translymphatic spread or in combination with SC, which reduces the size of tumor nodules, facilitating destruction by IPC. This may be an important mechanism that can explain the differential response in different tumors. Translymphatic spread is seen in tumors such as peritoneal mesothelioma, pseudomyxoma peritonei, and epithelial ovarian cancer, and these tumors are the most responsive to IPC. In limited colorectal PM, it may be less effective given the different mechanism of spread, namely, transmesothelial, which is in contrast to the aforementioned translymphatic route. ${ }^{48}$

Hyperthermia has many theoretical benefits. Heat itself is cytotoxic. It potentiates the cytotoxicity of the chemotherapeutic drugs, and in some instances helps in overcoming drug resistance. ${ }^{49-50}$ Despite clear demonstration of these benefits in preclinical models, the clinical benefit has not been validated in the treatment of PM. Because the hyperthermia clearly complicates the logistics of IPC, it needs further validation. Therefore, IPC should be regarded as an adjunct to surgery, SC, or both.

\section{HIPEC}

Hyperthermic intraperitoneal chemotherapy is the most controversial component of multi-modality treatment for PM. While evidence from randomized trials is accumulating in favor or disfavor of HIPEC, the procedure itself 
TABLE 1 Current indications for different methods of intraperitoneal chemotherapy

\begin{tabular}{|c|c|c|c|c|c|c|}
\hline $\begin{array}{l}\text { Type } \\
\text { of IPC }\end{array}$ & $\begin{array}{l}\text { Primary tumor } \\
\text { site }\end{array}$ & $\begin{array}{l}\text { Level of } \\
\text { evidence }\end{array}$ & $\begin{array}{l}\text { GRADE } \\
\text { of } \\
\text { evidence }^{\mathrm{a}}\end{array}$ & Comment on the GRADE & Timing of IPC & $\begin{array}{l}\text { Disease time } \\
\text { point(s) }\end{array}$ \\
\hline \multirow[t]{5}{*}{ HIPEC } & Colorectal & $1^{20-22,51}$ & Low & $\begin{array}{l}\text { One RCT was negative; one case- } \\
\text { controlled study with many limitations } \\
\text { showed a benefit of HIPEC over CRS } \\
\text { alone. }\end{array}$ & With CRS & $\begin{array}{l}\text { Metachronous/ } \\
\text { synchronous } \\
\text { PM }\end{array}$ \\
\hline & Stomach & $3^{23}$ & Low & $\begin{array}{l}\text { Based on the results of an observational } \\
\text { study in which propensity score- } \\
\text { matching was done for the confounding } \\
\text { factors, the HR was }>0.5 \text { for } \\
\text { CRS+HIPEC vs CRS alone. Hence the } \\
\text { GRADE of evidence is "low." }\end{array}$ & With CRS & $\begin{array}{l}\text { Synchronous } \\
\text { PM }\end{array}$ \\
\hline & Ovary & $1^{24}$ & Moderate & $\begin{array}{l}\text { Based on the results of one randomized } \\
\text { trial. The benefit in the primary end } \\
\text { point (PFS) was less than the benefit in } \\
\text { the secondary end point. }\end{array}$ & With CRS & Interval CRS \\
\hline & $\begin{array}{l}\text { Pseudomyxoma } \\
\text { peritonei }\end{array}$ & $3^{25-27}$ & Low & $\begin{array}{l}\text { Based on the results of an observational } \\
\text { study in which propensity score- } \\
\text { matching was done for the confounding } \\
\text { factors. The HR was }>0.5 \text { for } \\
\text { CRS+HIPEC vs CRS alone. Hence the } \\
\text { GRADE of evidence is "low." }\end{array}$ & With CRS & - \\
\hline & $\begin{array}{l}\text { Peritoneal } \\
\text { mesothelioma }\end{array}$ & $4^{28}$ & Low & $\begin{array}{l}\text { Although no study has evaluated the role } \\
\text { of HIPEC in addition to CRS, the } \\
\text { benefit of CRS-HIPEC over SC alone is } \\
\text { fourfold when historical data is } \\
\text { compared. Hence, the grade is low and } \\
\text { not "very low" for this very rare } \\
\text { disease }\end{array}$ & With CRS & - \\
\hline \multirow[t]{3}{*}{ NIPEC } & Ovary & $1^{29-32}$ & High & Based on the results of RCTs & Adjuvant therapy & $\begin{array}{l}\text { Primary and } \\
\text { interval CRS }\end{array}$ \\
\hline & Stomach & $4^{33}$ & Low & $\begin{array}{l}\text { Based on the results of prospective and } \\
\text { retrospective studies that do not have a } \\
\text { comparator arm and do not evaluate the } \\
\text { benefit of NIPEC alone }\end{array}$ & Neoadjuvant therapy & $\begin{array}{l}\text { Synchronous } \\
\text { PM }\end{array}$ \\
\hline & Colorectal & $1^{34}$ & Moderate & $\begin{array}{l}\text { Based on the results of one RCT that due } \\
\text { to poor accrual had to be closed } \\
\text { prematurely }\end{array}$ & Adjuvant therapy & $\begin{array}{l}\text { Metachronous/ } \\
\text { synchronous } \\
\text { PM }\end{array}$ \\
\hline PIPAC & $\begin{array}{l}\text { Various primary } \\
\text { tumors }\end{array}$ & $4^{35}$ & Low & $\begin{array}{l}\text { Based on the results of prospective and } \\
\text { retrospective studies that do not have a } \\
\text { comparator arm and do not evaluate the } \\
\text { benefit of PIPAC alone }\end{array}$ & $\begin{array}{l}\text { Neoadjuvant therapy for } \\
\text { unresectable disease; } \\
\text { palliation }\end{array}$ & $\begin{array}{l}\text { Synchronous/ } \\
\text { metachronous } \\
\text { PM }\end{array}$ \\
\hline
\end{tabular}

GRADE, Grading of Recommendations, Assessment, Development, and Evaluation; IPC, intraperitoneal chemotherapy; RCT, randomized controlled trial: HIPEC, hyperthermic intraperitoneal chemotherapy; CRS, cytoreductive surgery; PM, peritoneal metastases; HR, hazard ratio; NIPEC, normothermic intraperitoneal chemotherapy; PFS, progression-free survival; PIPAC, pressurized intraperitoneal aerosolized chemotherapy

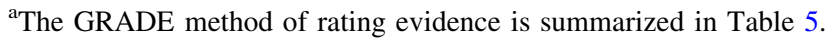

continues to be performed with a wide variation in the methodology, drugs, and other elements vital to the procedure. The recently published PRODIGE 7 trial did not show a benefit of adding HIPEC to CRS for patients with colorectal PM. ${ }^{51}$ One of the many questions raised about the trial has focused on the choice of drug regimen, and it has been proposed that an alternative regimen could have resulted in a positive outcome. ${ }^{52}$ This question is perhaps the most difficult to answer given the numerous regimens that have been used to perform HIPEC.

Having a limited number of regimens could increase the experience of the peritoneal oncology community, make comparison between studies more meaningful, and lead to a greater acceptance of the results from randomized trials. 
We performed a review of literature reporting the preclinical and clinical data on HIPEC regimens as well as studies and trials comparing different HIPEC regimens to determine the possibility of standardizing HIPEC regimens. Our aim was also to determine what the basis of such standardization should be and the best method for identifying a limited number of regimens that could be adopted by peritoneal malignancy centers across the world.

\section{METHODS}

A review of Pubmed, Medline, and Embase library databases was performed using the terms "HIPEC regimen," "HIPEC methodology," "HIPEC drugs," "peritoneal carcinomatosis," and "peritoneal metastases." The search aimed to identify preclinical studies that evaluate the pharmacokinetic aspects of different HIPEC drugs or drug regimens and those evaluating the impact of hyperthermia as well as the efficacy of different HIPEC regimens. For this study, clinical trials including phases 1 and 2 dose-finding studies and phases 2 and 3 randomized controlled trials, trials evaluating the efficacy of HIPEC, and trials comparing different drugs and drug regimens and HIPEC methodology were considered. Similarly, prospective and retrospective studies reporting on the same parameters (dose range, efficacy) and comparisons of different methodologies and regimens were considered. A critical appraisal of the available evidence was performed by the authors to identify the parameters pertaining to HIPEC methodology and regimens that need to be standardized as well as the best method of performing such a standardization.

\section{RESULTS}

This section, alongside the results of the literature search, describes the key technical aspects of performing HIPEC.

\section{HIPEC Methodology and Clinicopharmacologic Variables}

The HIPEC procedure involves the circulation of a heated chemotherapy solution in the peritoneal cavity for 30 to 120 min using a roller pump and heat exchanger (now custom-made machines). The abdomen is kept open, semiopen, or closed during the process. A number of clinical and pharmacologic variables influence the efficacy of the procedure. Unlike $\mathrm{SC}$, with the drug administered in a closed compartment, because the peritoneal cavity represents a huge space with a very variable volume according to the sex and body habitus. HIPEC is performed after
CRS, which involves resection of varying amounts of the peritoneum and adjacent viscera. Thus, variations in the methodology are inevitable, and the impact of different variables is difficult to quantify and control.

Pharmacologic Factors The impact of pharmacologic factors on the efficacy of HIPEC includes pharmacokinetic variables such as the drug (combination), dosage, molecular weight, carrier solution and its volume, application time and intraabdominal pressure, and pharmacodynamic variables such as tumor nodule size, density, vascularity, interstitial fluid pressure, binding, and temperature. $^{53}$

Drug Dosing Threshold and Peak Doses Drug dosing is based on preclinical and clinical data. Two dose limits should be considered: the "threshold dose," which is the minimum dose required to produce a therapeutic effect, and the "peak dose," which is the maximum dose above which additional therapeutic benefit is not observed or unacceptable toxicity is observed. ${ }^{54}$

The first method uses in vitro studies to determine the minimal toxic dose on cancer cell lines, and based on this, the IP dose is calculated. This is used as the threshold dose. The minimum or threshold dose of irinotecan is $50 \mathrm{mg} / \mathrm{m}^{2}$, and the threshold dose of mitomycin $\mathrm{C}$ is $10 \mathrm{mg} / \mathrm{m}^{2}$ (Table 2) ${ }^{55,56}$ For doxorubicin, the IP dose is much lower than the intravenous (IV) dose due to the risk of peritoneal sclerosis as doses exceed $15 \mathrm{mg} / \mathrm{m}^{257,58}$ No threshold dose of this drug is known. Subsequently, dose escalation studies are performed to determine the peak dose. ${ }^{59}$ The cell lines, however, have a major limitation of not capturing the tumor microenvironment, which has a major influence on the drug uptake and its efficacy.

The second method is to use the IV dose as a reference, and the baseline dose is a multiple of the IV dose. For oxaliplatin, the IV dose of $120 \mathrm{mg} / \mathrm{m}^{2}$ was used as a reference standard to develop two different regimens. The peak dose was $460 \mathrm{mg} / \mathrm{m}^{2}$ for a 30-min application and $200 \mathrm{mg} / \mathrm{m}^{2}$ for a 2 -h HIPEC. ${ }^{60,61}$ Similarly for cisplatin, $50 \mathrm{mg} / \mathrm{m}^{2}$ was used as the minimum dose, and further increments of $50 \%$ were tested for toxicity in two phase 1 trials. Notably, the dose-limiting toxicity was observed at different doses in the two trials, with each recommending a different ceiling dose. ${ }^{62,63}$ For gemcitabine, the IP dose required to achieve a target plasma level of the drug was used as a reference in one study, and the intravenous dose was used in other dose-finding studies. ${ }^{63-65}$

Both the threshold and peak doses are determined by a third (and probably most important) variable, namely, the duration of exposure. In the high-dose oxaliplatin regimen, the high dose of the drug was used to account for the short perfusion time. In an experimental study (unpublished 
TABLE 2 Peak and threshold doses of common drugs used in hyperthermic intraperitoneal chemotherapy (HIPEC) and their mode of calculation

\begin{tabular}{|c|c|c|c|c|}
\hline Drug & $\begin{array}{l}\text { Threshold dose }(\mathrm{mg} / \\
\left.\mathrm{m}^{2}\right)\end{array}$ & Mode of calculation & $\begin{array}{l}\text { Peak dose }(\mathrm{mg} / \\
\left.\mathrm{m}^{2}\right)\end{array}$ & $\begin{array}{l}\text { Mode of } \\
\text { determination }\end{array}$ \\
\hline Cisplatin $^{62,63}$ & 50 & Multiples/fraction of IV dose & 100 & Phase 1 studies \\
\hline Mitomycin $\mathrm{C}^{56}$ & 10 & $\begin{array}{l}\text { Dose required for minimum cell kill in the experimental } \\
\text { setting }\end{array}$ & 35 & Phase 1 studies \\
\hline Oxaliplatin $^{60,61}$ & 120 & Multiples /fraction of IV dose & 460 & Phase 1 studies \\
\hline Doxorubicin $^{51}$ & - & - & 15 & Phase 1 studies \\
\hline Gemcitabine $^{66-68}$ & 500 & Multiples/fraction of IV dose & 1500 & Clinical study ${ }^{\mathrm{a}}$ \\
\hline Melphalan $^{64,65}$ & 50 & Multiples/fraction of IV dose & 70 & Clinical study ${ }^{\mathrm{a}}$ \\
\hline Irinotecan $^{55,59}$ & 50 & $\begin{array}{l}\text { Dose required for minimum cell kill in the experimental } \\
\text { setting }\end{array}$ & 360 & Phase 1 study \\
\hline Paclitaxel $^{69-71}$ & 75 & Multiples/fraction of IV dose & 175 & Clinical study ${ }^{\mathrm{a}}$ \\
\hline Carboplatin $^{72}$ & 800 & Multiples /fraction of IV dose & 1200 & Phase 1 study \\
\hline Docetaxel $^{69,73}$ & 45 & Multiples/fraction of IV dose & 75 & Clinical study ${ }^{\mathrm{a}}$ \\
\hline
\end{tabular}

IV, intravenous

${ }^{\mathrm{a}}$ Clinical study that does not have the phase 1 design

data), 30 min of oxaliplatin HIPEC did not induce any significant apoptosis in tumor nodules in a rat model, but $200 \mathrm{mg} / \mathrm{m}^{2}$ at 90 and $120 \mathrm{~min}$ induced significant apoptosis.

For some drugs, such as mitomycin C, doxorubicin, and cisplatin, the lower doses are used when a combination of drugs is used to perform HIPEC. When a single agent is used, the peak dose usually is preferred.

Concentration-based or body surface area-based dosing. Conventionally, the drug dose is calculated using the body surface area (BSA) $\left(\mathrm{mg} / \mathrm{m}^{2}\right),{ }^{74,75}$ This calculation is based on the Dedrick formula, which shows a correlation between the BSA and the surface area of the peritoneum, However, a discrepancy exists in the BSA and the calculated peritoneal surface area, with variations observed according to the sex of the patients as well. ${ }^{74,75}$ Van der Speeten et al. $^{76}$ hypothesized that using a concentrationbased dose with a fixed volume of perfusate would be more efficacious than using a BSA-based dose in which the volume of perfusate remains variable. The COBOX trial showed an increased tumor uptake of oxaliplatin with a concentration-based regimen compared with the BSAbased regimen at $30 \mathrm{~min}$, with similar morbidity in the two groups.

Stat versus split dosing. Several studies have demonstrated that the peritoneal fluid drug concentration declines during the course of HIPEC. Therefore, instead of adding the entire dose at the beginning of the procedure, some surgeons add it in two or three installments to maintain a relatively constant peritoneal fluid concentration of the drug. ${ }^{56,77}$ The uptake of the drug by the tumor nodules is dependent on the peritoneal fluid concentration of the drug and the time of exposure. Although it is not possible to demonstrate the clinical benefit of split dosing over stat dosing, the former seems to be the more reasonable approach.

Perfusion Time The drug should remain in the peritoneal cavity for a sufficient time to obtain the maximum cell kill. This time is not set arbitrarily but according to the peritoneal half-life of the drug (Table 3). ${ }^{78}$ Prolonged exposure carries the risk of systemic toxicity, providing little benefit as the dose response curve plateaus. Application times for different drugs and regimens range from 30 to $120 \mathrm{~min}$, with $30 \mathrm{~min}$ currently considered "too short" by most surgeons. ${ }^{79}$ With the 30 -min high-dose oxaliplatin regimen, it was assumed that the high dosing with a strictly maintained temperature of $42-44{ }^{\circ} \mathrm{C}$ would lead to a fast absorption of the drug into the tumor nodules and rapid systemic clearance, thus making up for the short perfusion time. ${ }^{80}$ This regimen, after the negative results of three randomized trials, has been discarded by most surgeons and centers, although the regimen itself may not be the only cause of the negative results. ${ }^{1,81,82}$ This regimen still is one of the two regimens used in the CAIRO-6 trial. ${ }^{83}$ A longer perfusion time is necessary for the benefit of hyperthemia to be obtained, and the peritoneal half-life of most drugs is more than $30 \mathrm{~min}$ (40 min for oxaliplatin; 30-70 min for cisplatin). ${ }^{84}$

Carrier Solution The carrier solution used has an impact on the efficacy of IPC. An ideal carrier solution 
TABLE 3 GRADE of clinical evidence for various components of hyperthermic intraperitoneal chemotherapy (HIPEC) regimens

\begin{tabular}{lllllll}
\hline Drug & $\begin{array}{l}\text { Thermal } \\
\text { enhancement }\end{array}$ & $\begin{array}{l}\text { Clinical } \\
\text { benefit of } \\
\text { hyperthermia }\end{array}$ & $\begin{array}{l}\text { Perfusion } \\
\text { times (min) }\end{array}$ & $\begin{array}{l}\text { Comparison } \\
\text { between different } \\
\text { perfusion times }^{\mathrm{a}}\end{array}$ & $\begin{array}{l}\text { Comparison } \\
\text { between stat and } \\
\text { split dosing }^{\mathrm{a}}\end{array}$ & $\begin{array}{l}\text { Concentration-based } \\
\text { vs BSA-based dosing }^{\text {a }}\end{array}$ \\
\hline Cisplatin & Constant & Very low & $60 ; 90$ & Very low & Very low & Very low \\
Mitomycin C & Moderate & Very low & 90 & Very low & Very low & Very low \\
Oxaliplatin & Moderate & Very low & $30 ; 120$ & Very low & Very low & Moderate \\
Doxorubicin & Moderate & Very low & $90 ; 120$ & Very low & Very low & Very low \\
Gemcitabine & Moderate & Very low & 90 & Very low & Very low & Very low \\
Melphalan & Constant & Very low & $60 ; 90$ & Very low & Very low & Very low \\
Irinotecan & Moderate & Very low & 30 & Very low & Very low & Very low \\
Paclitaxel & Mild/none & Very low & 90 & Very low & Very low & Very low \\
Carboplatin & At high temperature & Very low & 90 & Very low & Very low & Very low \\
Docetaxel & Mild/none & Very low & 90 & Very low & Very low & Very low
\end{tabular}

GRADE, Grading of Recommendations, Assessment, Development, and Evaluation; BSA, body surface area

${ }^{\mathrm{a}}$ Grade of evidence could be high, moderate, low, or very low as elaborated in Table 5.

should lead to increased exposure of the peritoneal surface to the drug, should maintain a high intraperitoneal volume for a prolonged period, should be cleared slowly, and should not have a detrimental effect on the peritoneum itself. $^{85}$ The solution used can be hypotonic, isotonic, or hypertonic. ${ }^{86}$ Different carrier solutions have been used to deliver both low- and high-molecular-weight drugs. For example, both hypotonic and isotonic solutions have been used as carriers for oxaliplatin. Problems with each solution have been reported (with hypotonic solutions resulting in hyperglycemia and unexplained hemorrhage, and hypertonic solutions leading to chelation of the drug), and surgeons exercise their own preference for the carrier that is used. ${ }^{87-89}$

Volume of the Perfusate A volume of $1.5-2.51 / \mathrm{m}^{2}$ is required to perfuse all the peritoneal surfaces adequately. ${ }^{90}$ A higher perfusate volume limits the systemic absorption of the drug, whereas a lower volume hastens it. ${ }^{90}$ The dose and the volume of the perfusate are linked. Two options are possible:

1. The dose and volume of the perfusate are both BSAbased, resulting in a fixed drug concentration and thus a concentration-based IPC.

2. The dose is BSA-based, and the volume is determined by the volume of the abdominal cavity, resulting in a BSA-based IPC but with variable drug concentration.

Pressure In preclinical studies, it has been hypothesized and demonstrated that an increase in the intraabdominal pressure (IAP) during HIPEC can increase the intra-tumoral concentration and cytotoxicity of drugs such as cisplatin, oxaliplatin, and doxorubicin. ${ }^{91-94}$ No clinical study has shown the benefit of increasing the IAP. With an increase in the IAP beyond a point, respiratory and hemodynamic functions are compromised. With the closed method, the IAP is higher and can be increased using the flow rate and perfusate volume.

In a recently concluded phase 2 randomized study evaluating the impact of a raised IAP during HIPEC, Kusamura et al. ${ }^{95}$ showed an increased concentration of cisplatin in the mesenteric peritoneum in the study arm with a raised IAP, but a similar concentration in residual tumor nodules and the subperitoneal tissue in the two arms of the trial. The pharmacokinetic advantage and morbidity were similar in the two arms of the study. The oncologic advantage of such an approach remains to be demonstrated.

Temperature Numerous theoretical benefits are achieved by combining IPC and hyperthemia. Exposure to hyperthermia itself is cytotoxic to tumor cells by causing impairment of DNA repair, increased protein denaturation, lysosomal activation, and thus, apoptotic cell death. ${ }^{51}$

The drugs used for HIPEC undergo various degrees of thermal enhancement. Cisplatin, melphalan, and ifosfamide undergo constant thermal enhancement with increases in the temperature and are considered ideal drugs to combine with hyperthermia or "super drugs" for hyperthermia. ${ }^{52}$ Oxaliplatin and gemcitabine undergo thermal enhancement up to $41{ }^{\circ} \mathrm{C}$, which is moderate enhancement. ${ }^{96}$ For mitomycin $\mathrm{C}$ and doxorubicin, a threshold temperature of 41.5 ${ }^{\circ} \mathrm{C}$ is required for thermal enhancement. Others such as paclitaxel and docetaxel undergo very little or no thermal 
enhancement. Hyperthermia reduces the interstitial fluid pressure and increases the depth of drug penetration in tumor nodules. ${ }^{97,98}$ Hyperthermia with cisplatin can overcome platinum resistance, as shown by experimental data. ${ }^{99-101}$

Combining Chemotherapeutic Agents The combination of chemotherapeutic agents is based on even more limited preclinical and clinical data. ${ }^{102,103}$ The benefit of combining multiple agents has been demonstrated by the success of SC across tumor types, and the same rationale has been applied by surgeons to HIPEC. Some of the most common drug combinations used for HIPEC are cisplatin and doxorubicin, mitomycin $\mathrm{C}$ and doxorubicin, cisplatin and mitomycin $\mathrm{C}$, oxaliplatin and irinotecan, and cisplatin and paclitaxel. One retrospective study has shown the benefit of using the combination of two drugs versus using one drug alone for peritoneal mesothelioma. ${ }^{104}$ Another biinstitutional study showed no benefit of combining oxaliplatin and irinotecan versus using oxaliplatin alone. ${ }^{104}$

The recent propensity score-matched analysis of patients undergoing $\mathrm{CRS} \pm$ HIPEC for pseudomyxoma peritonei showed a survival benefit using the combination of cisplatin and mitomycin C. ${ }^{27}$ This combination is supported by experimental data showing that mitomycin enhances the intracellular accumulation of cisplatin and the production of platin DNA adducts. ${ }^{106-107}$ For the other combinations, no evidence or rationale exists for combining the two drugs. Often, these drugs have different thermal enhancement properties. For example, cisplatin is a super drug for hyperthemia compared with mitomycin and doxorubicin, which undergo moderate thermal enhancement.

\section{Bidirectional Intraoperative Chemotherapy Fre-} quently, HIPEC is combined with intravenous chemotherapy, which is administered just before the commencement of HIPEC or throughout its course. Intravenous chemotherapy reaches the tumor nodules through the systemic circulation and potentiates the effect of HIPEC. ${ }^{89}$ When IPC is performed under hyperthermic conditions, an intravenously delivered drug may profit from the local synergistic effect of hyperthermia. Many recent treatment protocols involve bidirectional intraoperative chemotherapy. ${ }^{108-110}$

\section{Nonpharmacologic Factors}

Extent of Peritoneal Resection In CRS, varying amounts of the parietal and visceral peritoneum are resected with or without resection of the adjacent or underlying viscera. It was assumed that once the peritoneal barrier (i.e., the peritoneal layer itself) has been removed, the diffusion of the drug into the systemic circulation should be greater. ${ }^{111}$

Subsequently. it has been shown that it is not the mesothelial layer itself but the sub-mesothelial tissue that constitutes the peritoneal barrier. Clinical studies have shown conflicting results. One study showed no impact of the extent of peritoneal resection, whereas others showed increased drug absorption when the extent of surgical resection was greater. ${ }^{111-114}$ Although, the absorption rates may vary, it is unlikely that adjustment of the drug dose is required after more extensive procedures because the difference in drug clearance is likely to be small.

Open Versus Closed Method Both open and closed methods of performing HIPEC have their advantages and disadvantages, and superiority of the one method over the other has not been proven. ${ }^{15,116}$ The studies have not accounted for the impact the method of performing HIPEC would have on the efficacy of HIPEC. After CRS, minimum/microscopic residual disease is targeted by HIPEC. The second role of HIPEC is to destroy the free intraperitoneal cancer cells shed during surgery and to prevent their implantation at the surgical sites. Experimental and clinical studies cannot demonstrate the impact of either technique on these cells. The choice of open versus closed method is dictated by the surgeon's preference, the availability of equipment, and the local governing regulations. ${ }^{117}$

Chemosensitivity Perhaps one of the most important factors is the sensitivity of the cancer cells to the chemotherapeutic drugs. Clinical and experimental data can determine only the drug concentration in tumor nodules. Drug concentration in tumor nodules cannot be assumed to be a measure of the regimen's efficacy (cell kill) This is one of the main problems with HIPEC because the drug or the regimen with the most suitable pharmacokinetic profile for HIPEC may not be the most effective in killing the cancer cells.

Initially, the drug concentration in peritoneal fluid was considered to be a measure of efficacy. Subsequently, it was the concentration in the tumor nodules, and some investigators currently are evaluating the utility of intratumoral apoptosis as a measure of efficacy. As mentioned earlier, the impact of HIPEC on the residual tumor nodules can be studied, but there is no way of studying its impact on free intraperitoneal cancer cells shed during CRS.

Cancer cell lines and xenograft models are far from accurate in predicting the effectiveness of a drug/HIPEC regimen. Recently, patient-derived tumor organoids have been used to study the efficacy of one HIPEC regimen compared with another. ${ }^{18,119}$ A biopsy sample from the patient's tumor is used to reconstruct not just the three- 
dimensional structure of the tumor, but also the surrounding stroma and its immune microenvironment. ${ }^{120}$ These organoids are then used to compare different regimens that may be used with or without hyperthermia, and thus to select the most effective regimen for the patient. A proofof-principle study has shown the $2-\mathrm{h} 200 \mathrm{mg} / \mathrm{m}^{2}$ oxaliplatin regimen to be more effective on the organoid platform than the $30-\mathrm{min}, 460 \mathrm{mg} / \mathrm{m}^{0}$ regimen. ${ }^{120}$ This approach still needs clinical validation, which will be a challenging task.

\section{Variations in HIPEC Regimens and Comparisons Between Different Regimens}

A systematic review reported the use of 60 different regimens for colorectal PM in 135 different publications. ${ }^{121}$ When the PRODIGE 7 trial did not show a benefit of short-duration, high-dose oxaliplatin HIPEC, many surgeons opined that the outcome could have been different with longer-duration mitomycin C HIPEC. ${ }^{1}$ A recent propensity score-matched analysis showed no benefit of mitomycin C HIPEC in colorectal PM. ${ }^{122}$ Another study showed the superiority of oxaliplatin HIPEC over mitomycin C HIPEC, whereas a third study showed a benefit of mitomycin C HIPEC for patients with a low Peritoneal Cancer Index (PCI). ${ }^{123,124}$

Given the heterogeneity of patients with colorectal PM as a whole, it is unlikely that the HIPEC regimen was the only factor that made a difference. For peritoneal mesothelioma, HIPEC using a combination of two drugs resulted in a significantly longer survival than HIPEC with a single drug. The choice of regimen can be based on the toxicity profile of each regimen. A randomized trial comparing oxaliplatin and mitomycin C HIPEC for appendiceal malignancies showed a higher hematologic toxicity with mitomycin, and the authors recommended mitomycin $\mathrm{C}$ HIPEC for patients with thrombocytopenia and oxaliplatin HIPEC for those with leucopenia (Table 4). ${ }^{125-127}$ For pseudomyxoma peritonei, the recent multi-institutional propensity score-matched study showed a survival benefit of the $30-\mathrm{min}, 460 \mathrm{mg} / \mathrm{m}^{2}$ oxaliplatin regimen with bidirectional 5-fluorouracil and the combination of cisplatin and mitomycin $\mathrm{C}$, but failed to show a benefit with lower doses of oxaliplatin and mitomycin $\mathrm{C}$ used as single agents. ${ }^{27}$ Head-to-head comparisons between the regimens were not performed in the study and it should not be inferred because the distribution of clinicopathologic features of groups receiving different regimens might not be homogeneous.

\section{DISCUSSION}

From the preceding discussion, it is clear that a multitude of permutations and combinations is possible and therefore a plethora of regimens can be used. There were many regimens neither supported by preclinical rationale/data nor validated by a dose-escalating formal phase 1 trial.

The HIPEC procedure should be considered a surgical therapy performed to destroy microscopic residual disease after CRS. Experimental studies can mimic the conditions in vivo only to a certain extent, and it is difficult to prove the benefit of one regimen or protocol over another. When HIPEC is performed with methodologic precision using an "adequate dose," maintenance of mild or moderate hyperthemia, and an adequate perfusion time, different regimens may produce the same or different results in different patients. This statement is borne out by the variability of the results obtained from the different clinical studies presented in Table 4.

\section{Future Research}

Comparison between the different HIPEC regimens will remain an area of future research, and such comparisons are best performed between specific subgroups of patients (e.g., patients with colorectal PM treated using HIPEC after neoadjuvant chemotherapy). The objective would be to find not only the best regimen but also the one that is best for each patient. In addition to randomized trials, which are challenging to conduct, more translational research and phases 1 and 2 studies are needed. The biologic mechanisms underlying the drug-heat interaction and chemotherapy cytotoxicity are areas that require further research. In contrast to the current mainstream "one-sizefits-all" policy, identification of factors predictive of treatment response and personalized medicine approaches like the use of organoids to determine the chemosensitivity of tumour cells to different HIPEC regimens could help in offering personalized treatment.

\section{Comparison with Systemic Chemotherapy}

Systemic chemotherapy involves administration of the drug in a closed compartment, with fewer pharmacokinetic and pharmacodynamic factors coming into play versus IPC. Despite this, the plasma levels, tumor concentrations, and half-lives vary significantly among patients. ${ }^{135}$ Findings have shown that drug elimination can vary up to fourfold between patients. ${ }^{136}$ Usually, BSA-based calculations are used for dosing, which are not very accurate and have the probability of under-dosing. ${ }^{137-139}$ Rounding of doses also is done, and it is unlikely that variations of 


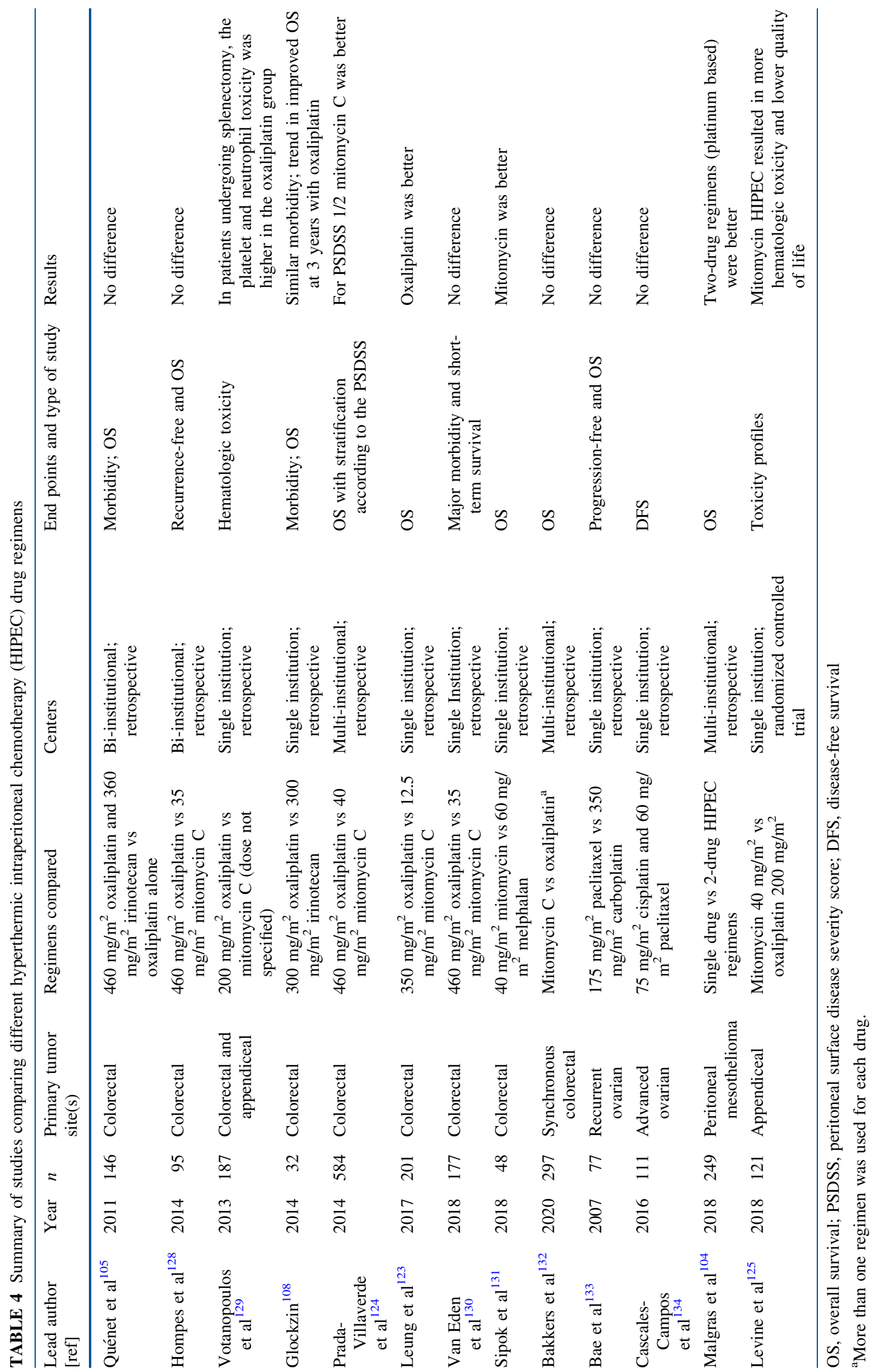


10-50 mg have a significant impact on the oncologic outcomes. $^{140}$

Some investigators have proposed that a range of fixed doses should be determined for use as a starting point. ${ }^{140}$ For patients prone to the development of complications, especially neutropenia, or for those with comorbidities, clinicians often start off with a dose lower than the standard dose. Dose reductions of 20-50\% are not uncommon, but can result in lower efficacy. ${ }^{141,142}$ A dose reduction of less than $50 \%$ is not recommended. ${ }^{140}$ Thus, although SC regimens for the adjuvant, neoadjuvant, and metastatic setting have been standardized, modifications and dose reductions are common and rampant.

\section{Standardization of HIPEC Regimens: The Need for an Expert Consensus}

Standardization of HIPEC regimens should result in the identification of only a few active regimens for each indication and should clearly define the methodology and all other parameters/variables of each regimen. The number of regimens can be reduced by eliminating regimens not supported by preclinical rationale/data and regimens not validated by a dose-escalating formal phase 1 trial.

With the multitude of factors having an impact on the efficacy of the procedure, it is difficult to have a few standardized regimens, as shown by the American Society of Peritoneal Surface Malignancies consensus for colorectal $\mathrm{PM}^{77}$ The Grading of Recommendations, Assessment, Development, and Evaluation (GRADE) system for rating quality of evidence could be used to rate the evidence for such a consensus, especially because the evidence is limited (Table 5). ${ }^{143,144}$ There are benefits from having uniform regimens, which can be determined by a consensus among the teams most experienced in performing these procedures. These benefits include the following:

- Larger combined experience of the peritoneal oncologic community and the scope for minimizing the morbidity.

- Larger evidence pool favoring or disfavoring the use of a particular regimen. Large-scale datasets of homogeneously performed procedures can fill the gap until we have (more) randomized controlled trials (RCTs) according to the 'Ideal Development, Exploration, Assessment, Long-term study (IDEAL)' framework. This homogeneity also can help in designing better RCTs.

- Adoption of a limited number of regimens. This will lead to greater acceptance of the results of RCTs by the oncology community at large.
- Selection of the regimen based on the anticipated toxicity in each patient. Each regimen has its own toxicity profile.

- Merging or comparison of data, which requires homogeneous treatment standards.

Modifications in HIPEC regimens will remain inevitable as with SC, largely to control of the morbidity Such modifications commonly comprise a reduction in the dose, a reduction maximum temperature, and a reduction in the duration of perfusion or a combination of one or more of these. The HIPEC procedure could be divided into the method of performing HIPEC and the HIPEC regimen itself. The former refers to the method (open or closed). For each method, the technical aspects such as properly placing the perfusion tubes, avoiding direct contact of the inflow channel with the bowel, ensuring proper perfusion of all areas, and maneuvering the bowel in the open method would constitute "methodologic accuracy" as previously described. $^{145,146}$

The HIPEC regimen includes the drug dose, the time or times of instillation, the choice of perfusate and its volume, the duration of perfusion, and the degree of hyperthermia. Three important components of HIPEC are hyperthermia, drug dose, and perfusion time, with adherence to a minimum standard for each component (Table 6).

Hyperthermia Mild or moderate hyperthermia should be used. Most regimens require the use of moderate hyperthermia $\left(41-43^{\circ} \mathrm{C}\right)$. Severe hyperthermia is not recommended. A temperature higher than $44{ }^{\circ} \mathrm{C}$ leads to cell death. ${ }^{147}$ For the procedure to be called HIPEC, the intraabdominal temperature should be at least $40{ }^{\circ} \mathrm{C}$.

Perfusion and Application Time All adhesions should be lysed to ensure that the maximum surface area of the peritoneum is exposed to the chemotherapy solution. During the open method, the small bowel loops are maneuvered to ensure uniform exposure to all peritoneal surfaces. As discussed earlier in this report, a perfusion time of 30 min currently is considered too short for the effect of heat to set in and for the perfusion of all peritoneal surfaces. The perfusion time of other regimens is also based on the peritoneal fluid half-life of the drug. The preferred perfusion times are 60 to $120 \mathrm{~min}$. Perfusion longer than 120 min could have more side effects with little additional benefit. ${ }^{148}$

Drug Dose The drug dose should be more than the threshold dose and less than the peak dose. Stat or split dosing can be used. The dose should be tailored to the volume of the perfusate to maintain an adequate concentration in the peritoneal fluid. The perfusion time 
TABLE 5 The GRADE method of rating clinical evidence (from refs 143 and144)

\begin{tabular}{ll}
$\begin{array}{l}\text { Assigned GRADE } \\
\text { quality }\end{array}$ & Description \\
\hline $\begin{array}{l}\text { High } \\
\text { Moderate }\end{array}$ & $\begin{array}{l}\text { Further research is very unlikely to change confidence in the estimate of effect } \\
\text { Further research is likely to have an important impact on confidence in the estimate of effect and may change the } \\
\text { estimate } \\
\text { Fow }\end{array}$ \\
Further research is very likely to have an important impact on confidence in the estimate of effect and is likely to \\
change
\end{tabular}

GRADE, Grading of Recommendations, Assessment, Development, and Evaluation

TABLE 6 Minimum standards for performing hyperthermic intraperitoneal chemotherapy (HIPEC)

\begin{tabular}{lll}
\hline Hyperthermia & Drug & Perfusion time \\
\hline Mild to moderate hyperthermia & Threshold and peak doses & Minimum and maximum perfusion times \\
& Stat or split dose & \\
Concentration-based dosing & \\
Acceptable drug combinations & \\
\hline
\end{tabular}

should be adequate as well. Other parameters such as type of perfusate, volume, and method of performing HIPEC should be selected as described earlier.

\section{SUMMARY AND CONCLUSIONS}

A certain degree of variability in HIPEC regimens and methodology may be inevitable but should be reduced. Randomized trials comparing different regimens are difficult to conduct, and it would be difficult to derive meaningful conclusions given the heterogeneity of the patient population itself. More preclinical and phases 1 and 2 studies are warranted. The biologic mechanisms underlying the drug-heat interaction and the cytotoxicity of chemotherapeutic agents need further study.

Until better evidence is available, the best way to minimize the heterogeneity in HIPEC protocols is by reaching an expert consensus that aims to identify and define a limited number of regimens for each indication and primary site. The GRADE method could be used to rate the evidence and consensus among the most experienced teams in the world based on the factors outlined in this report. Adoption of a limited number of regimens will increase the experience of the peritoneal oncology community as a whole, make comparison between studies more meaningful, and lead to greater acceptance of the results of randomized trials. The choice of regimen then can be tailored to the patient profile and expected toxicity of the regimen, and the methodology can be tailored according regional preferences, availability of equipment, and local governing regulations. Surgeons should focus on methodologic accuracy and the three key elements, namely, adequate drug dosing, maintenance of hyperthermia, and adequate perfusion.

The HIPEC regimens in current use are based on pharmacokinetic data and do not account for chemosensitivity. Personalized medicine approaches such as patient tumor organoids could offer a solution to this problem in the future, although clinical validation is likely be challenging.

\section{REFERENCES}

1. Spratt JD, Adcock RA, Muskovin M, Sherrill W, McKeown J. Clinical delivery system for intraperitoneal hyperthermic chemotherapy. Cancer Res. 1980;40:256-60.

2. Koga S, Shimizu N, Maeta M, Hamazoe R, Izumi A. Application of heat combined with antineoplastic agent administration in the treatment of cancer (with special reference to malignancy of the digestive system). Gan To Kagaku Ryoho. 1983;10(2 Pt 2):358-65.

3. Trenta P, Giovannoni S, Risi E, The CE role of systemic chemotherapy. In: Di Giorgio A, Pinto E, editors. Treatment of Peritoneal Surface Malignancies. State of the Art and Perspectives. Italia: Springer-Verlag; 2015. 
4. Speyer JL, Myers CE. The use of peritoneal dialysis for delivery of chemotherapy to intraperitoneal malignancies. Recent Results Cancer Res. 1980;74:264-9.

5. Katz MH, Barone RM. The rationale of perioperative intraperitoneal chemotherapy in the treatment of peritoneal surface malignancies. Surg Oncol Clin N Am. 2003;12:673-88.

6. Dedrick RL, Myers CE, Bungay PM, De Vita Jr. VT. Pharmacokinetic rationale for peritoneal drug administration in the treatment of ovarian cancer. Cancer Treat Rep. 1978;62:1-11.

7. Solass W, Horvath P, Struller F, Königsrainer I, Beckert S, Königsrainer A, et al. Functional vascular anatomy of the peritoneum in health and disease. Pleura Peritoneum. 2016;1:145-58. https://doi.org/10.1515/pp-2016-0015.

8. Stein MK, Williard FW, Xiu J, Tsao MW, Martin MG, Deschner $\mathrm{BW}$, et al. Comprehensive tumor profiling reveals unique molecular differences between peritoneal metastases and primary colorectal adenocarcinoma. $J$ Surg Oncol. 2020;121:1320-8. https://doi.org/10.1002/jso.25899.

9. Carr NJ, Bibeau F, Bradley RF, Dartigues P, Feakins RM, Geisinger KR, et al. The histopathological classification, diagnosis, and differential diagnosis of mucinous appendiceal neoplasms, appendiceal adenocarcinomas, and pseudomyxoma peritonei. Histopathology. 2017;71:847-58. https://doi.org/10.1 111/his.13324.

10. Kemp Z, Ledermann J. Update on first-line treatment of advanced ovarian carcinoma. Int $J$ Womens Health. 2013;5:45-51. https://doi.org/10.2147/IJWH.S30231.

11. Böhm S, Faruqi A, Said I, et al. Chemotherapy response score: development and validation of a system to quantify histopathologic response to neoadjuvant chemotherapy in tuboovarian high-grade serous carcinoma. J Clin Oncol. 2015;33:2457-63. https://doi.org/10.1200/JCO.2014.60.5212.

12. Bartlett DL. HIPEC: the complexities of clinical trials. Ann Surg Oncol. 2008;15:1277-9. https://doi.org/10.1245/s10434-007-97 68 -y.

13. Low RN, Barone RM, Rousset P. Peritoneal MRI in patients undergoing cytoreductive surgery and HIPEC: history, clinical applications, and implementation. Eur J Surg Oncol. 2019. h ttps://doi.org/10.1016/j.ejso.2019.02.030.

14. Honoré C, Gelli M, Francoual J, Benhaim L, Elias D, Goéré D. Ninety percent of the adverse outcomes occur in $10 \%$ of patients: can we identify the populations at high risk of developing peritoneal metastases after curative surgery for colorectal cancer? Int J Hyperthermia. 2017;33:505-10. https://doi.org/10. 1080/02656736.2017.1306119.

15. Seshadri RA, Glehen O. The role of hyperthermic intraperitoneal chemotherapy in gastric cancer. Ind J Surg Oncol. 2016;7:198-207. https://doi.org/10.1007/s13193-016-0502-8.

16. Franko J. Therapeutic efficacy of systemic therapy for colorectal peritoneal carcinomatosis: surgeon's perspective. Pleura Peritoneum. 2018;3:20180102. https://doi.org/10.1515/pp-20180102.PMID:30911652;PMCID:PMC6405010.

17. Franko J, Shi Q, Meyers JP, Maughan TS, Adams RA, Seymour MT, et al. Analysis and Research in Cancers of the Digestive System (ARCAD) group. Lancet Oncol. 2016;17:1709-19. htt ps://doi.org/10.1016/S1470-2045(16)30500-9.

18. Bhatt A, Rousset P, Benzerdjeb N, et al. Clinical and radiologic predictors of a pathologic complete response to neoadjuvant chemotherapy (NACT) in patients undergoing cytoreductive surgery for colorectal peritoneal metastases: results of a prospective multi-center study. Ann Surg Oncol. 2020. https://d oi.org/10.1245/s10434-020-09330-8.

19. Lemoine L, Sugarbaker P, van der Speeten K. Drugs, doses, and durations of intraperitoneal chemotherapy: standardising HIPEC and EPIC for colorectal, appendiceal, gastric, ovarian peritoneal surface malignancies and peritoneal mesothelioma. Int $J$
Hyperthermia. 2017;33(5):582-92. https://doi.org/10.1080/026 56736.2017.1291999.

20. Verwaal VJ, van Ruth S, de Bree E, et al. Randomized trial of cytoreduction and hyperthermic intraperitoneal chemotherapy versus systemic chemotherapy and palliative surgery in patients with peritoneal carcinomatosis of colorectal cancer. J Clin Oncol. 2003;21:3737-43. https://doi.org/10.1200/JCO.2003.04. 187.

21. Elias D, Gilly F, Boutitie F, et al. Peritoneal colorectal carcinomatosis treated with surgery and perioperative intraperitoneal chemotherapy: retrospective analysis of 523 patients from a multicentric French study. J Clin Oncol. 2010;28:63-8. https://d oi.org/10.1200/JCO.2009.23.9285.

22. Huang CQ, Feng JP, Yang XJ, Li Y. Cytoreductive surgery plus hyperthermic intraperitoneal chemotherapy improves survival of patients with peritoneal carcinomatosis from colorectal cancer: a case-control study from a Chinese center. J Surg Oncol. 2014;109:730-9. https://doi.org/10.1002/jso.23545.

23. Bonnot PE, Piessen G, Kepenekian V, Decullier E, Pocard M, Meunier B, et al. Cytoreductive surgery with or without hyperthermic intraperitoneal chemotherapy for gastric cancer with peritoneal metastases (CYTO-CHIP study): a propensity score analysis. J Clin Oncol. 2019;37:2028-40. https://doi.org/ 10.1200/JCO.18.01688.

24. van Driel WJ, Koole SN, Sikorska K, et al. Hyperthermic intraperitoneal chemotherapy in ovarian cancer. $N$ Engl J Med. 2018;378:230-40. https://doi.org/10.1056/NEJMoa1708618.

25. Kusamura S, Barretta F, Yonemura Y, Sugarbaker PH, Moran BJ, Levine EA, et al. The role of hyperthermic intraperitoneal chemotherapy in pseudomyxoma peritonei after cytoreductive surgery. JAMA Surg. 2021;156(3):e206363. https://doi.org/10.1 001/jamasurg.2020.6363.

26. Chua TC, Moran BJ, Sugarbaker PH, Levine EA, Glehen O, Gilly FN, et al. Early- and long-term outcome data of patients with pseudomyxoma peritonei from appendiceal origin treated by a strategy of cytoreductive surgery and hyperthermic intraperitoneal chemotherapy. J Clin Oncol. 2012;30:2449-56.

27. Yan TD, Black D, Savady R, Sugarbaker PH. A systematic review on the efficacy of cytoreductive surgery and perioperative intraperitoneal chemotherapy for pseudomyxoma peritonei. Ann Surg Oncol. 2007;14:484-92.

28. Yan TD, Deraco M, Baratti D, Sugarbaker PH, et al. Cytoreductive surgery and hyperthermic intraperitoneal chemotherapy for malignant peritoneal mesothelioma: multi-institutional experience. J Clin Oncol. 2009;27:6237-42.

29. Armstrong DK, Bundy B, Wenzel L, Huang HQ, Baergen R, Lele S, Gynecologic Oncology Group. Intraperitoneal cisplatin and paclitaxel in ovarian cancer. $N$ Engl $J$ Med. 2006;354:34-43. https://doi.org/10.1056/NEJMoa052985.

30. Walker JL, Brady MF, Wenzel L, Fleming GF, Huang HQ, DiSilvestro PA, et al. Randomized trial of intravenous versus intraperitoneal chemotherapy plus bevacizumab in advanced ovarian carcinoma: an NRG Oncology/Gynecologic Oncology Group study. J Clin Oncol. 2019;37:1380-90. https://doi.org/10. 1200/JCO.18.01568 (Erratum. In: J Clin Oncol. 2019;37:2299).

31. Alberts DS, Liu PY, Hannigan EV, et al. Intraperitoneal cisplatin plus intravenous cyclophosphamide versus intravenous cisplatin plus intravenous cyclophosphamide for stage III ovarian cancer. N Engl J Med. 1996;335:1950-5.

32. Markman M, Bundy BN, Alberts DS, et al. Phase III trial of standard-dose intravenous cisplatin plus paclitaxel versus moderately high-dose carboplatin followed by intravenous paclitaxel and intraperitoneal cisplatin in small-volume stage III ovarian carcinoma: an intergroup study of the Gynecologic Oncology 
Group, Southwestern Oncology Group, and Eastern Cooperative Oncology Group. J Clin Oncol. 2001;19:1001-7.

33. Cashin PH, Mahteme H, Spång N, Syk I, Frödin JE, Torkzad M, et al. Cytoreductive surgery and intraperitoneal chemotherapy versus systemic chemotherapy for colorectal peritoneal metastases: a randomised trial. Eur J Cancer. 2016;53:155-62. h ttps://doi.org/10.1016/j.ejca.2015.09.017.

34. Canbay E, Mizumoto A, Ichinose M, Ishibashi H, Sako S, Hirano M, et al. Outcome data of patients with peritoneal carcinomatosis from gastric origin treated by a strategy of bidirectional chemotherapy prior to cytoreductive surgery and hyperthermic intraperitoneal chemotherapy in a single specialized center in Japan. Ann Surg Oncol. 2014;21:1147-52.

35. Alyami M, Hübner M, Grass F, Bakrin N, Villeneuve L, Laplace $\mathrm{N}$, et al. Pressurised intraperitoneal aerosol chemotherapy: rationale, evidence, and potential indications. Lancet Oncol. 2019;20:e368-77. https://doi.org/10.1016/S1470-2045(19)3031 8-3.

36. Flessner MF. The transport barrier in intraperitoneal therapy. Am J Physiol Renal Physiol. 2005;288:F433-42.

37. Flessner MF. Intraperitoneal drug therapy: physical and biological principles. Cancer Treat Res. 2007;134:131-52.

38. Yonemura Y. Trans-lymphatic metastasis. In: Yonemura Y, editor. Atlas and principles of peritonectomy for peritoneal surface malignancy. Kyoto: NPO to support peritoneal surface malignancy; 2012. p. 188-206.

39. Yonemura Y, Canbay E, Endou Y, et al. Mechanisms of the formation of peritoneal surface malignancy on omental milky spots from low-grade appendiceal mucinous carcinoma. J Clin Exp Oncol. 2014;3:3. https://doi.org/10.4172/2324-9110. 1000130.

40. Solass W, Herbette A, Schwarz T, Hetzel A, Sun JS, Dutreix M, Reymond MA. Therapeutic approach of human peritoneal carcinomatosis with Dbait in combination capnoperitoneum: proof of concept. Surg Endosc. 2012;26:847-52. https://doi.org/10.1 007/s00464-011-1964-y.

41. Khosrawipour V, Khosrawipour T, Diaz-Carballo D, Forster E, Zieren J, Giger-Pabst U. Exploring the spatial drug distribution pattern of pressurized Intraperitoneal aerosol chemotherapy (PIPAC). Ann Surg Oncol. 2016;23:1220-4.

42. Khosrawipour V, Khosrawipour T, Kern AJ, Osma A, Kabakci B, Diaz-Carballo D, et al. Distribution pattern and penetration depth of doxorubicin after pressurized intraperitoneal aerosol chemotherapy (PIPAC) in a postmortem swine model. J Cancer Res Clin Oncol. 2016;142:2275-80. https://doi.org/10.1007/s00 432-016-2234-0.

43. Göhler D, Khosrawipour V, Khosrawipour T, et al. Technical description of the microinjection pump ( $\mathrm{MIP}^{\circledR}$ ) and granulometric characterization of the aerosol applied for pressurized intraperitoneal aerosol chemotherapy (PIPAC). Surg Endosc. 2017;31:1778-84. https://doi.org/10.1007/s00464-016-5174-5.

44. Alyami M, Mercier F, Siebert M, Bonnot PE, Laplace N, Villeneuve L, et al. Unresectable peritoneal metastasis treated by pressurized intraperitoneal aerosol chemotherapy (PIPAC) leading to cytoreductive surgery and hyperthermic intraperitoneal chemotherapy. Eur J Surg Oncol. 2021;47:128-33. h ttps://doi.org/10.1016/j.ejso.2019.06.028.

45. Valle M, Van der Speeten K, Garofalo A. Laparoscopic hyperthermic peroperative chemotherapy (HIPEC) in the management of refractory malignant ascites: a multi-institutional analysis in 52 patients. J Surg Oncol. 2009;100:331-4.

46. Schneebaum S, Arnold MW, Staubus A, Young DC, Dumond D, Martin EW Jr. Intraperitoneal hyperthermic perfusion with mitomycin $\mathrm{C}$ for colorectal cancer with peritoneal metastases. Ann Surg Oncol. 1996;3:44-50.
47. Sugarbaker PH. Normothermic intraperitoneal chemotherapy long term (NIPEC-LT) in the management of peritoneal surface malignancy: an overview. Pleura Peritoneum. 2017;22:85-93. h ttps://doi.org/10.1515/pp-2017-0012.

48. Yonemura Y, Sako S, Wakama S, Ishibashi H, Mizumoto A, Takao N, et al. History of peritoneal surface malignancy treatment in Japan. J Surg Oncol. 2019;10(Suppl 1):3-11.

49. Sticca RP, Dach BW. Rationale for hyperthermia with intraoperative intraperitoneal chemotherapy agents. Surg Oncol Clin N Am. 2003;12:689-701.

50. Sugarbaker PH. Laboratory and clinical basis for hyperthermia as a component of intracavitary chemotherapy. Int $J$ Hyperth. 2007;23:431-42.

51. Quénet F, Elias D, Roca L, et al. Cytoreductive surgery plus hyperthermic intraperitoneal chemotherapy versus cytoreductive surgery alone for colorectal peritoneal metastases (PRODIGE 7): a multicentre, randomised, open-label, phase 3 trial. Lancet Oncol. 2021. https://doi.org/10.1016/S1470-2045(20)30599-4.

52. Konisgrainer A, Rau B. Cytoreductive surgery (CRS) and hyperthermic intraperitoneal chemotherapy (HIPEC): don't throw the baby out with the bathwater. Pleura Peritoneum. 2018;3(4):20180131. https://doi.org/10.1515/pp-2018-0131.

53. de Bree E, Michelakis D, Stamatiou D, Romanos J, Zoras O. Pharmacological principles of intraperitoneal and bidirectional chemotherapy. Pleura Peritoneum. 2017;2:47-62. https://doi.or g/10.1515/pp-2017-0010.

54. Budman DR. Dose and schedule as determinants of outcomes in chemotherapy for breast cancer. Semin Oncol. 2004;31(6 Suppl 15):3-9. https://doi.org/10.1053/j.seminoncol.2004.11.021.

55. Le Page S, Kwiatkowski F, Paulin C, Mohamed F, Pezet D, Chipponi J, et al. In vitro thermochemotherapy of colon cancer cell lines with irinotecan alone and combined with mitomycin C. Hepatogastroenterology. 2006;53:693-7.

56. Witkamp A. Dose finding study of hyperthermic intraperitoneal chemotherapy with mitomycin C in patients with carcinosis of colorectal origin. Eur J Surg Oncol. 1998;24:214.

57. Johansen PB. Doxorubicin pharmacokinetics after intravenous and intraperitoneal administration in the nude mouse. Cancer Chemother Pharmacol. 1981;5:267-70.

58. Van der Speeten K, Stuart OA, Mahteme H, Sugarbaker PH. A pharmacologic analysis of intraoperative intracavitary cancer chemotherapy with doxorubicin. Cancer Chemother Pharmacol. 2009;63:799-805. https://doi.org/10.1007/s00280-008-0800-0.

59. Cotte E, Passot G, Tod M, Bakrin N, Gilly FN, Steghens A, et al. Closed abdomen hyperthermic intraperitoneal chemotherapy with irinotecan and mitomycin C: a phase I study. Ann Surg Oncol. 2011;18:2599-603. https://doi.org/10.1245/s10434-0111651-1.

60. Elias D, Bonnay M, Puizillou JM, Antoun S, Demirdjian S, El $\mathrm{OA}$, et al. Heated intraoperative intraperitoneal oxaliplatin after complete resection of peritoneal carcinomatosis: pharmacokinetics and tissue distribution. Ann Oncol. 2002;13:267-72.

61. Stewart JH, Shen P, Russell GB, et al. A Phase I trial of oxaliplatin for intraperitoneal hyperthermic chemoperfusion for the treatment of peritoneal surface dissemination from colorectal and appendiceal cancer. Ann Surg Oncol. 2008;15:2137-45.

62. Zivanovic O, Abramian A, Kullmann M, Fuhrmann C, Coch C, Hoeller T, et al. HIPEC ROC I: a phase i study of cisplatin administered as hyperthermic intraoperative intraperitoneal chemoperfusion followed by postoperative intravenous platinum-based chemotherapy in patients with platinum-sensitive recurrent epithelial ovarian cancer. Int $J$ Cancer. 2014;136:699-708.

63. Gouy S, Ferron G, Glehen O, Bayar A, Marchal F, Pomel C, et al. Results of a multicenter phase I dose-finding trial of hyperthermic intraperitoneal cisplatin after neoadjuvant 
chemotherapy and complete cytoreductive surgery and followed by maintenance bevacizumab in initially unresectable ovarian cancer. Gynecol Oncol. 2016;142:237-42. https://doi.org/10.10 16/j.ygyno.2016.05.032.

64. Glehen O, Stuart OA, Mohamed F, Sugarbaker PH. Hyperthermia modifies pharmacokinetics and tissue distribution of intraperitoneal melphalan in a rat model. Cancer Chemother Pharmacol. 2004;54:79-84.

65. Bijelic L, Sugarbaker PH, Stuart OA. Hyperthermic intraperitoneal chemotherapy with melphalan: a summary of clinical and pharmacological data in 34 patients. Gastroenterol Res Pract. 2012;2012:827534. https://doi.org/10.1155/2012/827534.

66. Sugarbaker PH, Stuart OA, Bijelic L. Intraperitoneal gemcitabine chemotherapy treatment for patients with resected pancreatic cancer: rationale and report of early data. Int J Surg Oncol. 2011;2011:161862. https://doi.org/10.1155/2011/ 161862.

67. Sabbatini P, Aghajanian C, Leitao M, Venkatraman E, Anderson $\mathrm{S}$, Dupont J, et al. Intraperitoneal cisplatin with intraperitoneal gemcitabine in patients with epithelial ovarian cancer: results of a phase I/II trial. Clin Cancer Res. 2004;10:2962-7.

68. Morgan RJ Jr, Synold TW, Xi B, Lim D, Shibata S, Margolin K, et al. Phase I trial of intraperitoneal gemcitabine in the treatment of advanced malignancies primarily confined to the peritoneal cavity. Clin Cancer Res. 2007;13:1232-7.

69. Mohamed F, Marchettini P, Stuart OA, Urano M, Sugarbaker PH. Thermal enhancement of new chemotherapeutic agents at moderate hyperthermia. Ann Surg Oncol. 2003;10:463-8. http s://doi.org/10.1245/aso.2003.08.006.

70. De Bree E, Theodoropoulos PA, Rosing H, Michalakis J, Romanos J, Beijnen JH, et al. Treatment of ovarian cancer using intraperitoneal chemotherapy with taxanes: from laboratory bench to bedside. Cancer Treat Rev. 2006;32:471-82.

71. De Bree E, Rosing H, Michalakis J, Romanos J, Relakis K, Theodoropoulos PA, et al. Intraperitoneal chemotherapy with taxanes for ovarian cancer with peritoneal dissemination. Eur J Surg Oncol. 2006;32:666-70.

72. Steller M, Egorin M, Trimble E, et al. A pilot phase I trial of continuous hyperthermic peritoneal perfusion with high-dose carboplatin as primary treatment of patients with small-volume residual ovarian cancer. Cancer Chemother Pharmacol. 1999;43:106-14. https://doi.org/10.1007/s002800050870.

73. de Bree E, Rosing H, Beijnen JH, Romanos J, Michalakis J, Georgoulias V, Tsiftsis DD. Pharmacokinetic study of docetaxel in intraoperative hyperthermic ip chemotherapy for ovarian cancer. Anticancer Drugs. 2003;14:103-10. https://doi.org/10. 1097/00001813-200302000-00003.

74. Albanese AM, Albanese EF, Mino JH, et al. Peritoneal surface area: measurements of 40 structures covered by peritoneum: correlation between total peritoneal surface area and the surface calculated by formulas. Surg Radiol Anat. 2009;31:369-77.

75. Ates K, Erturk S, Nergisoglu G, et al. Sex-dependent variations in peritoneal membrane transport properties in CAPD patients. Nephrol Dialysis Transplant. 1996;11:2375-6.

76. Lemoine L, Thijssen E, Carleer R, Geboers K, Sugarbaker P, van der Speeten K. Body surface area-based vs concentrationbased perioperative intraperitoneal chemotherapy after optimal cytoreductive surgery in colorectal peritoneal surface malignancy treatment: COBOX trial. $J$ Surg Oncol. 2019;119:999-1010. https://doi.org/10.1002/jso.25437.

77. Turaga K, Levine E, Barone R, Sticca R, Petrelli N, Lambert L, et al. Consensus guidelines from the American Society of Peritoneal Surface Malignancies on standardizing the delivery of hyperthermic intraperitoneal chemotherapy (HIPEC) in colorectal cancer patients in the United States. Ann Surg Oncol. 2014;21:1501-5.
78. Van der Speeten K, Stuart OA, Sugarbaker PH. Pharmacokinetics and pharmacodynamics of perioperative cancer chemotherapy in peritoneal surface malignancy. Cancer J. 2009;15:216-24. https://doi.org/10.1097/PPO.0b013e3181a58d 95.

79. Ceelen W. HIPEC with oxaliplatin for colorectal peritoneal metastasis: the end of the road? Eur J Surg Oncol. 2019;45:400-2. https://doi.org/10.1016/j.ejso.2018.10.542.

80. Elias DM, Sideris L. Pharmacokinetics of heated intraoperative intraperitoneal oxaliplatin after complete resection of peritoneal carcinomatosis. Surg Oncol Clin North Am. 2003;12:755-69.

81. Goéré D, Glehen O, Quenet F, Guilloit JM, Bereder JM, Lorimier G, et al. Second-look surgery plus hyperthermic intraperitoneal chemotherapy versus surveillance in patients at high risk of developing colorectal peritoneal metastases (PROPHYLOCHIP-PRODIGE 15): a randomised, phase 3 study. Lancet Oncol. 2020;21:1147-54. https://doi.org/10.1016/S14702045(20)30322-3.

82. Klaver CEL, Wisselink DD, Punt CJA, Snaebjornsson P, Crezee $\mathrm{J}$, Aalbers AGJ, et al. Adjuvant hyperthermic intraperitoneal chemotherapy in patients with locally advanced colon cancer (COLOPEC): a multicentre, open-label, randomised trial. COLOPEC Collaborators Group. Lancet Gastroenterol Hepatol. 2019;4:761-70. https://doi.org/10.1016/S24681253(19)30239-0.

83. Rovers KP, Bakkers C, Simkens GAAM, et al. Perioperative systemic therapy and cytoreductive surgery with HIPEC versus upfront cytoreductive surgery with HIPEC alone for isolated resectable colorectal peritoneal metastases: protocol of a multicentre, open-label, parallel-group, phase II-III, randomised, superiority study (CAIRO6). BMC Cancer. 2019;19:390. http s://doi.org/10.1186/s12885-019-5545-0.

84. Cashin PH, Ehrsson H, Wallin I, et al. Pharmacokinetics of cisplatin during hyperthermic intraperitoneal treatment of peritoneal carcinomatosis. Eur J Clin Pharmacol. 2013;69:533-40. https://doi.org/10.1007/s00228-012-1405-4.

85. Mohamed F, Sugarbaker PH. Carrier solutions for intraperitoneal chemotherapy. Surg Oncol Clin N Am. 2003;12:813-24.

86. Pestieau SR, Schnake KJ, Stuart OA, Sugarbaker PH. Impact of carrier solutions on the pharmacokinetics of intraperitoneal chemotherapy. Cancer Chemother Pharmacol. 2001;47:269-76.

87. Tsujitani S, Oka A, Kondo A, Katano K, Oka S, Saito H, et al. Administration in a hypotonic solution is preferable to dose escalation in intraperitoneal cisplatin chemotherapy for peritoneal carcinomatosis in rats. Oncology. 1999;57:77-82.

88. Elias D, El Otmany A, Bonnay M, Paci A, Ducreux M, Antoun $S$, et al. Human pharmacokinetic study of heated intraperitoneal oxaliplatin in increasingly hypotonic solutions after complete resection of peritoneal carcinomatosis. Oncology. 2002;63:346-52.

89. Mehta AM, Van den Hoven JM, Rosing H, Hillebrand MJ, Nuijen B, Huitema AD, Beijnen JH, Verwaal VJ. Stability of oxaliplatin in chloride-containing carrier solutions used in hyperthermic intraperitoneal chemotherapy. Int $J$ Pharm. 2015;479:23-7. https://doi.org/10.1016/j.ijpharm.2014.12.025.

90. Sugarbaker PH, Stuart OA, Carmignani CP. Pharmacokinetic changes induced by the volume of chemotherapy solution in patients treated with hyperthermic intraperitoneal mitomycin $\mathrm{C}$. Cancer Chemother Pharmacol. 2006;57:703-8.

91. Dedrick RL, Flessner MF. Pharmacokinetic problems in peritoneal drug administration: tissue penetration and surface exposure. J Natl Cancer Inst. 1997;89:480-7.

92. Esquis P, Consolo D, Magnin G, Pointaire P, Moretto P, Ysna $\mathrm{MD}$, et al. High intraabdominal pressure enhances the penetration and antitumor effect of intra-peritoneal cisplatin on experimental carcinomatosis. Ann Surg. 2006;244:106-12. 
93. Jacquet P, Stuart OA, Chang D, Sugarbaker PH. Effect of intraabdominal pressure on pharmacokinetics and tissue distribution of doxorubicin after intra-peritoneal administration. AntiCancer Drugs. 1996;7:596-603.

94. Gesson-Paute A, Ferron G, Thomas F, de Lara EC, Chatelut E, Querleu D. Pharmacokinetics of oxaliplatin during open versus laparoscopically assisted heated intraoperative chemotherapy (HIPEC): an experimental study. Ann Surg Oncol. 2008;15:339-44.

95. Kusamura S, Azmi N, Fumagalli L, Baratti D, Guaglio M, Cavalleri $\mathrm{A}$, et al. Phase II randomized study on tissue distribution and pharmacokinetics of cisplatin according to different levels of intraabdominal pressure (IAP) during HIPEC (NCT02949791). Eur J Surg Oncol. 2021;47:82-8. https://doi. org/10.1016/j.ejso.2019.06.022.

96. Urano M, Kuroda M, Nishimura Y. For the clinical application of thermochemotherapy given at mild temperatures. Int $J$ Hyperth. 1999;15:79-107.

97. Young JS, Lumsden CE, Stalker AL. The significance of the tissue pressure of normal testicular and of neoplastic (BrownPearce carcinoma) tissue in the rabbit. $J$ Pathol Bacteriol. 1950;62:313-33.

98. Leunig M, Goetz AE, Dellian M, Zetterer G, Gamarra F, Jain RK, Messmer K. Interstitial fluid pressure in solid tumors following hyperthermia: possible correlation with therapeutic response. Cancer Res. 1992;52:487-90.

99. Hettinga VE. Reduction of Cisplatin Resistance by Hyperthermia. PhD Thesis, University of Groningen (ISBN 90-367-06483). Printpartners Ipskamp bv, Enschede, 1996.

100. Hetting VE, Lemstra W, Meijer C, et al. Mechanism of hyperthermic potentiation of cisplatin action in cisplatin sensitive and -resistant tumor cells. Br J Cancer. 1997;75:1735-43.

101. Hettinga JV, Konings AW, Kampinga HH. Reduction of cellular cisplatin resistance by hyperthermia: a review. Int J Hyperth. 1997;13:439-57.

102. Elias D, Raynard B, Bonnay M, Pocard M. Heated intraoperative intraperitoneal oxaliplatin alone and in combination with intraperitoneal irinotecan: pharmacologic studies. Eur J Surg Oncol. 2006;32:607-13.

103. Ansaloni L, Coccolini F, Morosi L, et al. Pharmacokinetics of concomitant cisplatin and paclitaxel administered by hyperthermic intraperitoneal chemotherapy to patients with peritoneal carcinomatosis from epithelial ovarian cancer. $\mathrm{Br} \mathrm{J}$ Cancer. 2015;112:306-12. https://doi.org/10.1038/bjc.2014.602.

104. Malgras B, Gayat E, Aoun O, Lo Dico R, Eveno C, Pautrat K, et al. Impact of combination chemotherapy in peritoneal mesothelioma hyperthermic intraperitoneal chemotherapy (HIPEC): The RENAPE study: RENAPE Network. Ann Surg Oncol. 2018;25:3271-9. https://doi.org/10.1245/s10434-018-66 31-2.

105. Quénet F, Goéré D, Mehta SS, Roca L, Dumont F, Hessissen M, et al. Results of two bi-institutional prospective studies using intraperitoneal oxaliplatin with or without irinotecan during HIPEC after cytoreductive surgery for colorectal carcinomatosis. Ann Surg. 2011;254:294-301. https://doi.org/10.1097/SLA. 0b013e3182263933.

106. Saikawa Y, Kubota T, Kuo TH, et al. Synergistic antitumor activity of mitomycin $\mathrm{C}$ and cisplatin against gastric cancer cells in vitro. J Surg Oncol. 1993;54:98-102. https://doi.org/10.1002/ jso.2930540209.

107. Saikawa Y, Kubota T, Kuo TH, et al. Synergistic antitumor activity of combination chemotherapy with mitomycin $\mathrm{C}$ and cisplatin against human gastric cancer xenografts in nude mice. J Surg Oncol. 1994;56:242-5. https://doi.org/10.1002/jso. 2930560408.
108. Glockzin G, Gerken M, Lang SA, Klinkhammer-Schalke M, Piso P, Schlitt HJ. Oxaliplatin-based versus irinotecan-based hyperthermic intraperitoneal chemotherapy (HIPEC) in patients with peritoneal metastasis from appendiceal and colorectal cancer: a retrospective analysis. BMC Cancer. 2014;14:807.

109. Hakeam H, Ayman A, Waleed AT, Amen T. Systemic complications of the bidirectional intraoperative chemotherapy with intravenous ifosfamide and hyperthermic intraperitoneal chemotherapy (HIPEC) using cisplatin plus doxorubicin. Pleura Peritoneum. 2019;4:20190025. https://doi.org/10.1515/pp-20190025.

110. Van der Speeten K, Lemoine L. HIPEC Methodology, comparison of techniques, and drug regimens: is there a need for standardization? In: A Bhatt, editor. Management of peritoneal metastases: cytoreductive surgery, HIPEC, and beyond. Singapore: Springer; 2018.

111. Jacquet P, Sugarbaker PH. Peritoneal-plasma barrier. Cancer Treat Res. 1996;82:53-63.

112. De Lima Vazquez V, Stuart OA, Mohamed F, Sugarbaker PH. Extent of parietal peritonectomy does not change intraperitoneal chemotherapy pharmacokinetics. Cancer Chemother Pharmacol. 2003;52:108-12.

113. Jacquet P, Averbach A, Stephens AD, Stuart OA, Chang D, Sugarbaker $\mathrm{PH}$. Heated intraoperative intraperitoneal mitomycin $\mathrm{C}$ and early postoperative intraperitoneal 5-fluorouracil: pharmacokinetic studies. Oncology. 1998;55:130-8.

114. Sugarbaker PH, Van Der Speeten K, Anthony Stuart O, Chang D. Impact of surgical and clinical factors on the pharmacology of intraperitoneal doxorubicin in 145 patients with peritoneal carcinomatosis. Eur J Surg Oncol. 2011;37:719-26.

115. Villa AF, El Balkhi S, Aboura R, Sageot H, Hasni-Pichard H, Pocard M, et al. Evaluation of oxaliplatin exposure of healthcare workers during heated intraperitoneal perioperative chemotherapy (HIPEC). Ind Health. 2015;53:28-37.

116. Elias D, Antoun S, Goharin A, Otmany AE, Puizillout JM, Lasser P. Research on the best chemohyperthermia technique of treatment of peritoneal carcinomatosis after complete resection. Int J Surg Investig. 2000;1:431-9.

117. Leiting JL, Cloyd JM, Ahmed A, Fournier K, Lee AJ, Dessureault $\mathrm{S}$, et al. Comparison of open and closed hyperthermic intraperitoneal chemotherapy: results from the United States hyperthermic intraperitoneal chemotherapy collaborative. World J Gastrointest Oncol. 2020;12:756-67.

118. Ubink I, Bolhaqueiro ACF, Elias SG, Raats DAE, Constantinides A, Peters NA, et al. Organoids from colorectal peritoneal metastases as a platform for improving hyperthermic intraperitoneal chemotherapy. Br J Surg. 2019;106:1404-14. https://doi. org/10.1002/bjs. 11206 .

119. Votanopoulos KI, Mazzocchi A, Sivakumar H, et al. Appendiceal cancer patient-specific tumor organoid model for predicting chemotherapy efficacy prior to initiation of treatment: a feasibility study. Ann Surg Oncol. 2019;26:139-47. https://doi. org/10.1245/s10434-018-7008-2.

120. Forsythe SD, Sasikumar S, Moaven O, et al. Personalized identification of optimal HIPEC perfusion protocol in patientderived tumor organoid platform. Ann Surg Oncol. 2020;27:4950-60. https://doi.org/10.1245/s10434-020-08790-2.

121. Yurttas C, Hoffmann G, Tolios A, Haen SP, Schwab M, Königsrainer I, et al. Systematic review of variations in hyperthermic intraperitoneal chemotherapy (HIPEC) for peritoneal metastasis from colorectal cancer. J Clin Med. 2018;7:567. h ttps://doi.org/10.3390/jcm7120567.

122. Baratti D, Kusamura S, Azmi N, Guaglio M, Montenovo M, Deraco M. Colorectal peritoneal metastases treated by perioperative systemic chemotherapy and cytoreductive surgery with or without mitomycin C-based HIPEC: a comparative study 
using the Peritoneal Surface Disease Severity Score (PSDSS). Ann Surg Oncol. 2020;27:98-106. https://doi.org/10.1245/s104 34-019-07935-2.

123. Leung V, Huo YR, Liauw W, Morris DL. Oxaliplatin versus mitomycin $\mathrm{C}$ for HIPEC in colorectal cancer peritoneal carcinomatosis. Eur J Surg Oncol. 2017;43:144-9. https://doi.org/10. 1016/j.ejso.2016.09.015.

124. Prada-Villaverde A, Esquivel J, Lowy AM, Markman M, Chua T, Pelz J, et al. The American Society of Peritoneal Surface Malignancies evaluation of HIPEC with mitomycin $\mathrm{C}$ versus oxaliplatin in 539 patients with colon cancer undergoing a complete cytoreductive surgery. Surg Oncol. 2014;110:779-85. https://doi.org/10.1002/jso.23728.

125. Levine EA, Votanopoulos KI, Shen P, et al. A multicenter randomized trial to evaluate hematologic toxicities after hyperthermic intraperitoneal chemotherapy with oxaliplatin or mitomycin in patients with appendiceal tumors (published correction appears in J Am Coll Surg. 2018;227:633). J Am Coll Surg. 2018;226:434-43. https://doi.org/10.1016/j.jamcollsurg.2 017.12.02.

126. Chalret du Rieu Q, White-Koning M, Picaud L, Lochon I, Marsili S, Gladieff L, et al. Population pharmacokinetics of peritoneal, plasma ultrafiltrated, and protein-bound oxaliplatin concentrations in patients with disseminated peritoneal cancer after intraperitoneal hyperthermic chemoperfusion of oxaliplatin following cytoreductive surgery: correlation between oxaliplatin exposure and thrombocytopenia. Cancer Chemother Pharmacol. 2014;74:571-82.

127. Charrier T, Passot G, Peron J, Maurice C, Gocevska S, Quenet $\mathrm{F}$, et al. Cytoreductive surgery combined with hyperthermic intraperitoneal chemotherapy with oxaliplatin increases the risk of postoperative hemorrhagic complications: analysis of predictive factors. Ann Surg Oncol. 2016;23:2315-22.

128. Hompes D, D'Hoore A, Wolthuis A, Fieuws S, Mirck B, Bruin $\mathrm{S}$, Verwaal V. The use of oxaliplatin or mitomycin C in HIPEC treatment for peritoneal carcinomatosis from colorectal cancer: a comparative study. J Surg Oncol. 2014;109:527-32. https://doi. org/10.1002/jso.23546.

129. Votanopoulos K, Ihemelandu C, Shen P, Stewart J, Russell G, Levine EA. A comparison of hematologic toxicity profiles after heated intraperitoneal chemotherapy with oxaliplatin and mitomycin C. J Surg Res. 2013;179:e133-9. https://doi.org/10.1016/ j.jss.2012.01.015.

130. van Eden WJ, Kok NFM, Woensdregt K, Huitema ADR, Boot $\mathrm{H}$, Aalbers AGJ. Safety of intraperitoneal mitomycin C versus intraperitoneal oxaliplatin in patients with peritoneal carcinomatosis of colorectal cancer undergoing cytoreductive surgery and HIPEC. Eur J Surg Oncol. 2018;44:220-7. https://doi.org/ 10.1016/j.ejso.2017.10.216.

131. Sipok A, Sardi A, Nieroda C, King MC, Sittig M, Gushchin V. Comparison of survival in patients with isolated peritoneal carcinomatosis from colorectal cancer treated with cytoreduction and melphalan or mitomycin $\mathrm{C}$ as hyperthermic intraperitoneal chemotherapy agent. Int J Surg Oncol, 2018;2018:1920276. https://doi.org/10.1155/2018/1920276.

132. Bakkers C, van Erning FN, Rovers KP, Nienhuijs SW, Burger JW, Lemmens VE, et al. Long-term survival after hyperthermic intraperitoneal chemotherapy using mitomycin $\mathrm{C}$ or oxaliplatin in colorectal cancer patients with synchronous peritoneal metastases: a nationwide comparative study. Eur J Surg Oncol. 2020;46(10 Pt A):1902-7. https://doi.org/10.1016/j.ejso.2020.0 4.018 .

133. Bae JH, Lee JM, Ryu KS, et al. Treatment of ovarian cancer with paclitaxel- or carboplatin-based intraperitoneal hyperthermic chemotherapy during secondary surgery. Gynecol Oncol. 2007;106:193-200.
134. Cascales-Campos P, López-López V, Gil J, Arévalo-Pérez J, Nieto A, Barceló F, et al. Hyperthermic intraperitoneal chemotherapy with paclitaxel or cisplatin in patients with stage III-C/IV ovarian cancer: is there any difference? Surg Oncol. 2016;25:164-70. https://doi.org/10.1016/j.suronc.2016.05.010.

135. Gurney H, Ackland S, Liddle C, Dunleavey R, Rivory L, Farlow $\mathrm{D}$, et al. Determining the drug elimination phenotype: hepatic sestamibi scan and midazolam clearance as in vivo tests for drug metabolism and biliary elimination (abstract). Proc Am Soc Clin Oncol. 2001;20:305.

136. Gurney HP, Ackland S, Gebski V, Farrell G. Factors affecting epirubicin pharmacokinetics and toxicity: evidence against using body-surface area for dose calculation. J Clin Oncol. 1998;16:2299-3004.

137. Ratain MJ. Body surface area as a basis for dosing of anticancer agents: science, myth, or habit? J Clin Oncol. 1998;16:2297-8.

138. Gurney H. Dose calculation of anticancer drugs: a review of the current practice and introduction of an alternative. J Clin Oncol. 1996;14:2590-611.

139. Horwich A, Sleijfer DT, Fossa SD, Kaye SB, Oliver RT, Cullen $\mathrm{MH}$, et al. Randomized trial of bleomycin, etoposide, and cisplatin compared with bleomycin, etoposide, and carboplatin in good-prognosis metastatic non-seminomatous germ cell cancer: a Multi-institutional Medical Research Council/European Organization for Research and Treatment of Cancer trial. J Clin Oncol. 1997; 15:1844-52.

140. Gurney H. How to calculate the dose of chemotherapy. $\mathrm{Br} \mathrm{J}$ Cancer. 2002;86:1297-302. https://doi.org/10.1038/sj.bjc. 6600139.

141. Liutkauskiene S, Grizas S, Jureniene K, et al. Retrospective analysis of the impact of anthracycline dose reduction and chemotherapy delays on the outcomes of early breast cancer molecular subtypes. BMC Cancer. 2018;18:453. https://doi.org/ 10.1186/s12885-018-4365-y.

142. Munker S, Gerken M, Fest P, et al. Chemotherapy for metastatic colon cancer: no effect on survival when the dose is reduced due to side effects. BMC Cancer. 2018;18:455. https://doi.org/10. 1186/s12885-018-4380-z.

143. Atkins D, Best D, Briss PA, Eccles M, Falck-Ytter Y, Flottorp S, et al. Grading quality of evidence and strength of recommendations. BMJ. 2004;328:1490. https://doi.org/10.1136/bmj.328. 7454.1490 .

144. Guyatt G, Oxman AD, Akl EA, Kunz R, Vist G, Brozek J, et al. GRADE guidelines: 1. Introduction: GRADE evidence profiles and summary of findings tables. $J$ Clin Epidemiol. 2011;64:383-94. https://doi.org/10.1016/j.jclinepi.2010.04.026.

145. Glehen O, Cotte E, Kusamura S, Deraco M, Baratti D, Passot G, et al. Hyperthermic intraperitoneal chemotherapy: nomenclature and modalities of perfusion. J Surg Oncol. 2008;98:242-6.

146. Glehen O, Osinsky D, Cotte E, Kwiatkowski F, Freyer G, Isaac $\mathrm{S}$, et al. Intraperitoneal chemohyperthermia using a closed abdominal procedure and cytoreductive surgery for the treatment of peritoneal carcinomatosis: morbidity and mortality analysis of 216 consecutive procedures. Ann Surg Oncol. 2003;10:863-9.

147. Shimizu T, Maeta M, Koga S. Influence of local hyperthermia on the healing of small intestinal anastomoses in the rat. $\mathrm{Br} \mathrm{J}$ Surg. 1991;78:57-9.

148. De Bree E, Tsiftsis DD. Principles of perioperative intraperitoneal chemotherapy for peritoneal carcinomatosis. Recent Results Cancer Res. 2007;169:39-51.

Publisher's Note Springer Nature remains neutral with regard to jurisdictional claims in published maps and institutional affiliations. 